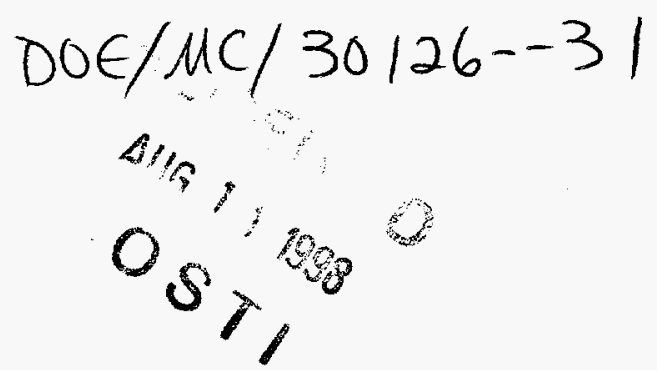

\title{
Preliminary Evaluation of a Process Using Plasma Reactions to Desulfurize Heavy Oils
}

\author{
Final Report \\ September 1997
}

\author{
By: \\ R. Will Grimes \\ Francis P. Miknis
}

Work Performed Under Contract No.: DE-FC21-93MC30126

\author{
For \\ U.S. Department of Energy \\ Office of Fossil Energy \\ Federal Energy Technology Center \\ P.O. Box 880 \\ Morgantown, West Virginia 26507-0880 \\ By \\ Western Research Institute \\ 365 North Ninth Street \\ Laramie, Wyoming 82071
}

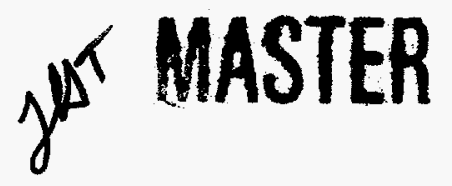




\section{Disclaimer}

This report was prepared as an account of work sponsored by an agency of the United States Government. Neither the United States Government nor any agency thereof, nor any of their employees, makes any warranty, express or implied, or assumes any legal liability or responsibility for the accuracy, completeness, or usefulness of any information, apparatus, product, or process disclosed, or represents that its use would not infringe privately owed rights. Reference herein to any specific commercial product, process, or service by trade name, trademark, manufacturer, or otherwise does not necessarily constitute or imply its endorsement, recommendation, or favoring by the United States Government or any agency thereof. The views and opinions of authors expressed herein do not necessarily state or reflect those of the United States Government or any agency thereof. 


\section{DISCLAIMER}

Portions of this document may be illegible electronic image products. Images are produced from the best available original document. 


\section{TABLE OF CONTENTS}

$\underline{\text { Page }}$

LIST OF TABLES AND FIGURES …………………….......................................... iv

EXECUTIVE SUMMARY ......................................................................

INTRODUCTION

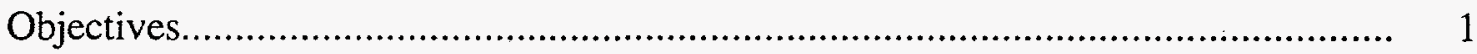

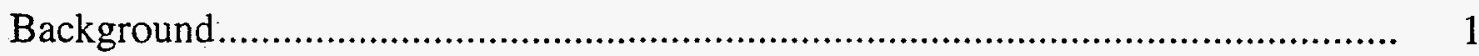

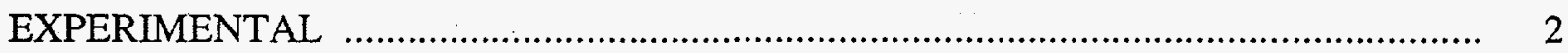

Feedstock Materials....................................................................................... 2

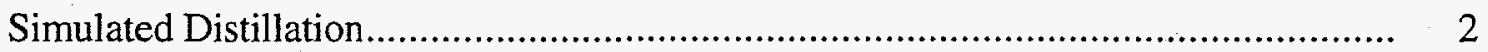

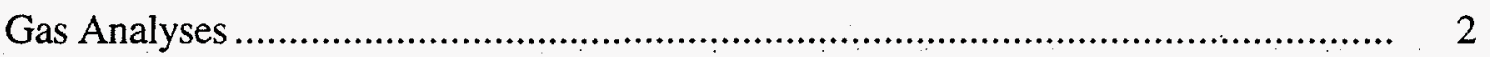

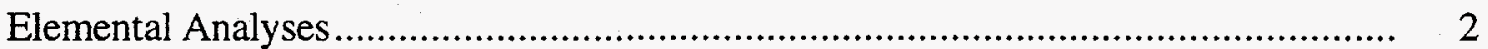

Experimental Procedures ............................................................................... 3

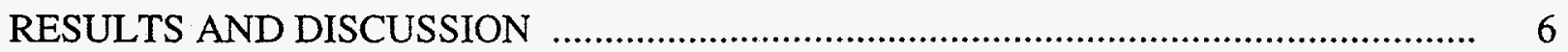

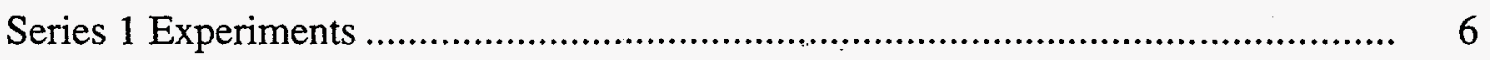

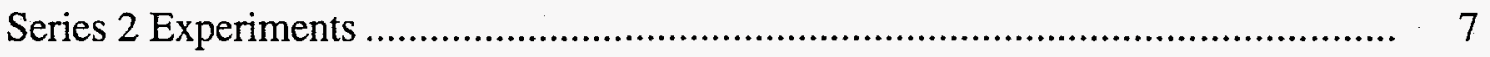

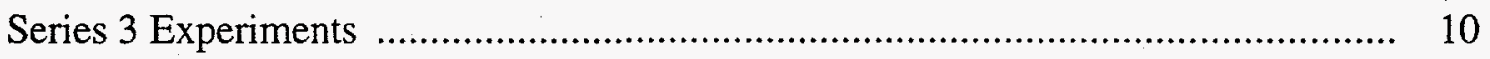

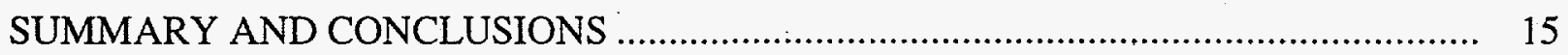

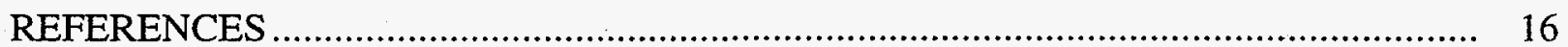




\section{LIST OF TABLES AND FIGURES}

Table

$\underline{\text { Page }}$

1. Conversion and Product Distribution for Series 1 Experiments ............................... 6

2. $\mathrm{C}, \mathrm{H}, \mathrm{N}, \mathrm{S}$ Analyses of Combined Liquid Products From Series 1 Experiments......... 6

3. Conversion and Product Distribution for Series 2 Experiments .............................. 8

4. Experimental Conditions, Conversion, and Product Distribution for Series 3

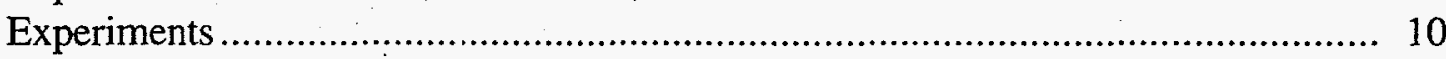

5. $\mathrm{C}, \mathrm{H}, \mathrm{N}, \mathrm{S}$ Analyses of Distillate Product From Selected Series 3 Experiments ......... 13

6. C,H,N,S Analyses of Methylene Chloride Soluble Resid From Selected Series 3 Experiments

7. $\mathrm{C}, \mathrm{H}, \mathrm{N}, \mathrm{S}$ Analyses of Methylene Chloride Insoluble Solids From Series 3 Experiments

1. Batch Reactor System.

2. Block Diagram of Microwave Apparatus.......................................................... 5

3. Schematic Diagram of Gas Flow System ......................................................... 5

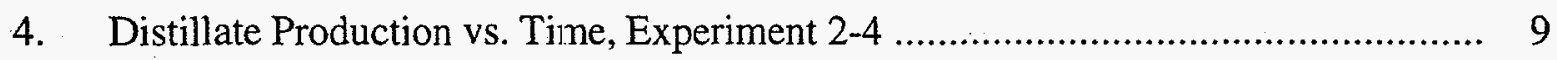

5. Results of Simulated Distillation of Distillate Product from Series 2 Experiments ... 9 


\section{EXECUTIVE SUMMARY}

Western Research Institute (WRI) has conducted exploratory experiments on the use of microwave-induced plasmas to desulfurize heavy oils. Batch mode experiments were conducted in a quartz reactor system using various reactive and nonreactive plasmas. In these experiments a high-sulfur asphalt was exposed to various plasmas, and the degree of conversion to distillate, gas, and solids was recorded. Products from selected experiments were analyzed to determine if the plasma exposure had resulted in a significant reduction in sulfur content.

Exploratory experiments were conducted using reactive plasmas generated from hydrogen and methane and nonreactive plasmas generated from nitrogen. The effects of varying exposure duration, sample temperature, and location of the sample with respect to the plasma discharge were investigated. For comparative purposes two experiments were conducted in which the sample was heated under nitrogen with no plasma exposure.

The experiments using reactive (hydrogen and methane) plasmas consistently produced more distillate than similar experiments using nonreactive nitrogen plasmas. Sample temperature had a minimal effect on conversion to distillate in these exploratory experiments. The location of the sample with respect to the discharge strongly affected conversion and product distribution. Typically conversions increased as the distance between the sample and the discharge was decreased. This held true for both the reactive and the nonreactive plasmas. Total (100\%) conversion of the sample to gas and solids resulted when the sample was placed within the discharge. Under these conditions no distillate was produced.

Distillate containing approximately $28 \%$ less sulfur than the feedstock represented the maximum desulfurization attained in the plasma experiments. This same level of desulfurization was also attained by heating the sample under nitrogen with no plasma exposure. For similar conversions, heating the sample under nitrogen with no plasma exposure generated more distillate and less gas than either the reactive or nonreactive plasmas. From these exploratory experiments it does not appear that plasma reactions using the simple configurations employed in this study represent a viable method for the desulfurization of heavy oils. 


\section{INTRODUCTION}

\section{Objective}

The objective of this task was to provide data needed to assess the potential viability of a process to desulfurize heavy oils through the use of plasma reactions.

\section{Background}

Due to a continuing decline in supplies of sweet light crude, heavy oils are becoming increasingly important as refinery feedstock. Unfortunately, heavy oils tend to be considerably more difficult to process than the lighter crudes. The physical and chemical properties of heavy oils differ significantly from those of lighter crudes, and therefore, their use presents some special challenges for refiners. Heavy oils are typically characterized as containing less hydrogen and considerably more sulfur, nitrogen, oxygen, and metals than the lighter crudes. The high levels of sulfur typically found in heavy oils is of particular significance in the refining process.

Sulfur is undesirable in liquid fuel products for a number of reasons and is also frequently responsible for corrosion problems in refinery equipment. To meet the demand for low-sulfur distillate products and reduce corrosion problems, many petroleum refineries have incorporated a feedstock desulfurization process. A number of processes can decrease sulfur levels in refinery feedstock (Speight 1981), however, hydrodesulfurization processes are most commonly employed for this purpose.

Hydrodesulfurization processes remove sulfur through the catalytic reaction of hydrogen with sulfur-containing constituents of the petroleum. The gaseous hydrogen sulfide produced by this reaction is separated from the liquid products to yield hydrocarbons with greatly reduced sulfur content. The relative ease of the gas/liquid separation and the high level of sulfur removal typically achieved by the process have led to a nearly universal acceptance of hydrodesulfurization as the best method for desulfurizing petroleum.

Application of hydrodesulfurization processes to heavy oils is compromised by the deposition of coke and metals on the catalyst. These deposits tend to deactivate the catalyst, necessitating frequent regeneration and/or replacement, which adds considerably to the cost of desulfurization. Thus, for the heavy oils for which desulfurization is most necessary, the best available process has significant shortcomings. A desulfurization process that removes sulfur as hydrogen sulfide without the use of catalysts could represent an important step forward in the use of heavy oils as refinery feedstock.

Studies conducted by Amano and co-workers (Amano et al. 1984 and 1985) have shown that hydrogen atoms generated in a microwave discharge can react directly with coal to produce 
liquids that are practically free of heteroatoms. These experiments suggest that $H$ atoms generated in a microwave discharge might also react with other hydrocarbon-containing materials, such as heavy oils and petroleum resids, to produce low-sulfur liquid products.

Exploratory experiments were conducted to determine whether low-sulfur liquid products can be obtained by reacting a heavy oil feedstock material in hydrogen-rich microwave plasmas. In the various experiments, a high-sulfur asphalt feedstock was exposed to microwave plasmas generated using hydrogen $\left(\mathrm{H}_{2}\right)$, methane $\left(\mathrm{CH}_{4}\right)$, and nitrogen $\left(\mathrm{N}_{2}\right)$. Reaction products were analyzed to determine if the plasma exposure resulted in significant desulfurization. The results of these experiments are the subject of this topical report.

\section{EXPERIMENTAL}

\section{Feedstock Material}

A high-sulfur asphalt obtained from the Strategic Highway Research Program (SHRP) Materials Reference Library (Cominsky et al. 1989) was used as feedstock in all the experiments.

\section{$\underline{\text { Simulated Distillation }}$}

This procedure is a gas chromatographic technique for determining distillation profiles of materials that are not $100 \%$ distillable below $544 \mathrm{~K}$. The chromatographic data are divided into desired distillate fractions from correlations between gas chromatography (GC) retention times and normal alkane boiling points. The concentration (weight percent) of each distillate fraction is determined using response factors obtained from standard samples. The results are reported as concentration (weight percent) of distillable materials versus temperature. The boiling ranges are chosen to correspond to those of the true boiling point distillation (Gary and Handwerk 1975).

\section{Gas Analyses}

Gas samples were analyzed using a Hewlett-Packard 5840-A gas chromatograph equipped with a flame photometric detector. Sulfur gases were analyzed on a $10 \mathrm{ft} \times 1 / 8 \mathrm{in}$. carbopak BHT column. Nitrogen carrier gas flow rate was $30 \mathrm{cc} / \mathrm{min}$. The column oven was temperature programmed to hold at $20^{\circ} \mathrm{C}$ for three minutes then heat at $25^{\circ} \mathrm{C} / \mathrm{min}$ to $120^{\circ} \mathrm{C}$.

\section{Elemental Analyses}

Carbon, hydrogen, and nitrogen were determined with a Perkin-Elmer 2400 automated CHN analyzer. Calibration was done with acetanilide, benzoic acid, carbazole, cholesteryl palmitate, and steric acid. Sulfur was determined with a Fisher 475 sulfur analyzer according to 
American Society for Testing and Materials (ASTM) D4239. Oil standards from Alpha Chemical were used for calibration. Oxygen was determined by difference.

\section{Experimental Procedures}

The batch reactor shown schematically in Figure 1 was used for the majority of the experiments. The reactor consisted of two coaxial quartz tubes. The 19-mm o.d. (16.5-mm i.d.) outer tube was sealed at one end to form an elongated test tube that served as the sample holder. The 9-mm o.d. (6.5-mm i.d.) interior tube provided a flow path for the plasma so that its tail (the glow remaining outside the microwave field) could be made to impinge upon the surface of the heavy oil sample. The interior tube was attached to the outer tube by means of a stainless steel fitting with O-ring seals. The axial adjustment provided by this arrangement allowed the distance from the end of the interior tube to the sample to be varied.

Using various feed gases and feed gas combinations, microwave energy was used to generate plasmas. The system used to deliver microwave energy to the plasma consisted of a terminated waveguide applicator (Haugsjaa 1986) microwave generator, magnetic circulator, directional coupler, impedance matching device, and various waveguide sections. Figure 2 is a block diagram of the microwave system used in the testing.

Microwave energy was supplied by a Cober s6F industrial microwave generator. The generator power output was adjustable from 0 to $6 \mathrm{~kW}$ at a fixed frequency of $2.45 \mathrm{GHz}$. The generator was connected via a magnetic circulator and a Microwave Techniques twin stub tuner to a terminated waveguide applicator. The applicator was constructed by boring a $22-\mathrm{mm}$ hole through the center of the broad faces of a standard WR284 waveguide termination. The distance from the center of the hole to the shorted end was equal to one half the width of the broad face.

The gas flow system is shown schematically in Figure 3. A Brooks 5850E mass flow controller was used to regulate and measure the inlet gas flow. A saturator and bypass completed the flow system upstream of the reactor. Downstream from the reactor condensable liquid products were collected in a 10-mL cold trap immersed in a slurry of dry ice and methanol. A rubber septum was provided through which grab samples of the product gas could be withdrawn by means of a gas-tight syringe. A throttle valve, vacuum trap, and rotary pump completed the downstream flow system. Reactor pressure was recorded using an Omega Q-15 pressure transducer connected to a strip chart recorder.

Three series of experiments were conducted using the batch reactor system and a highsulfur asphalt feedstock. Series 1 experiments were conducted to determine if various hydrogenrich microwave plasmas would selectively abstract sulfur from a high-sulfur asphalt material. Series 2 and 3 experiments were conducted to determine the effect of sample temperature and distance between discharge and sample on conversion to distillate and desulfurization. 


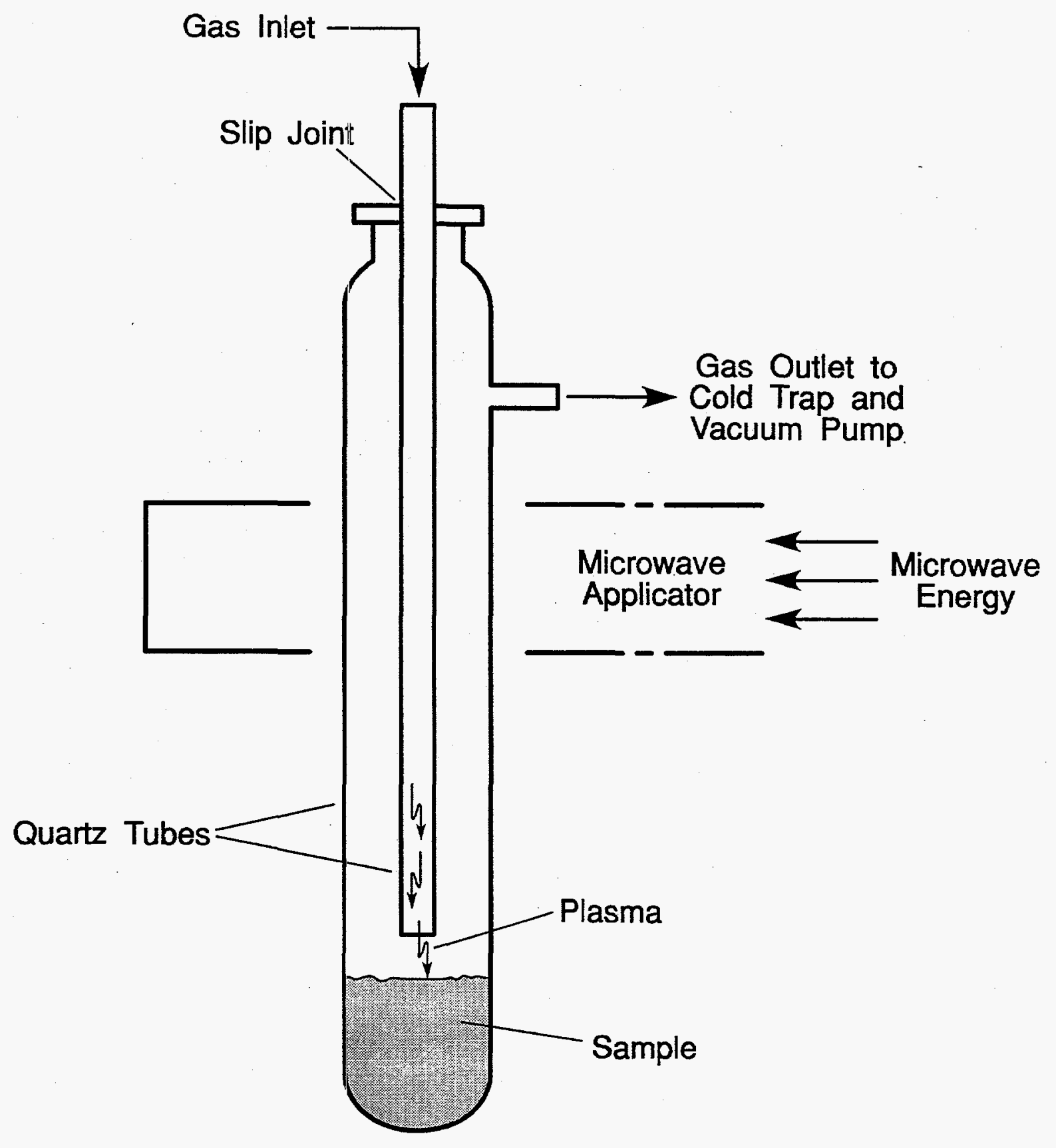

Figure 1. Batch Reactor System 


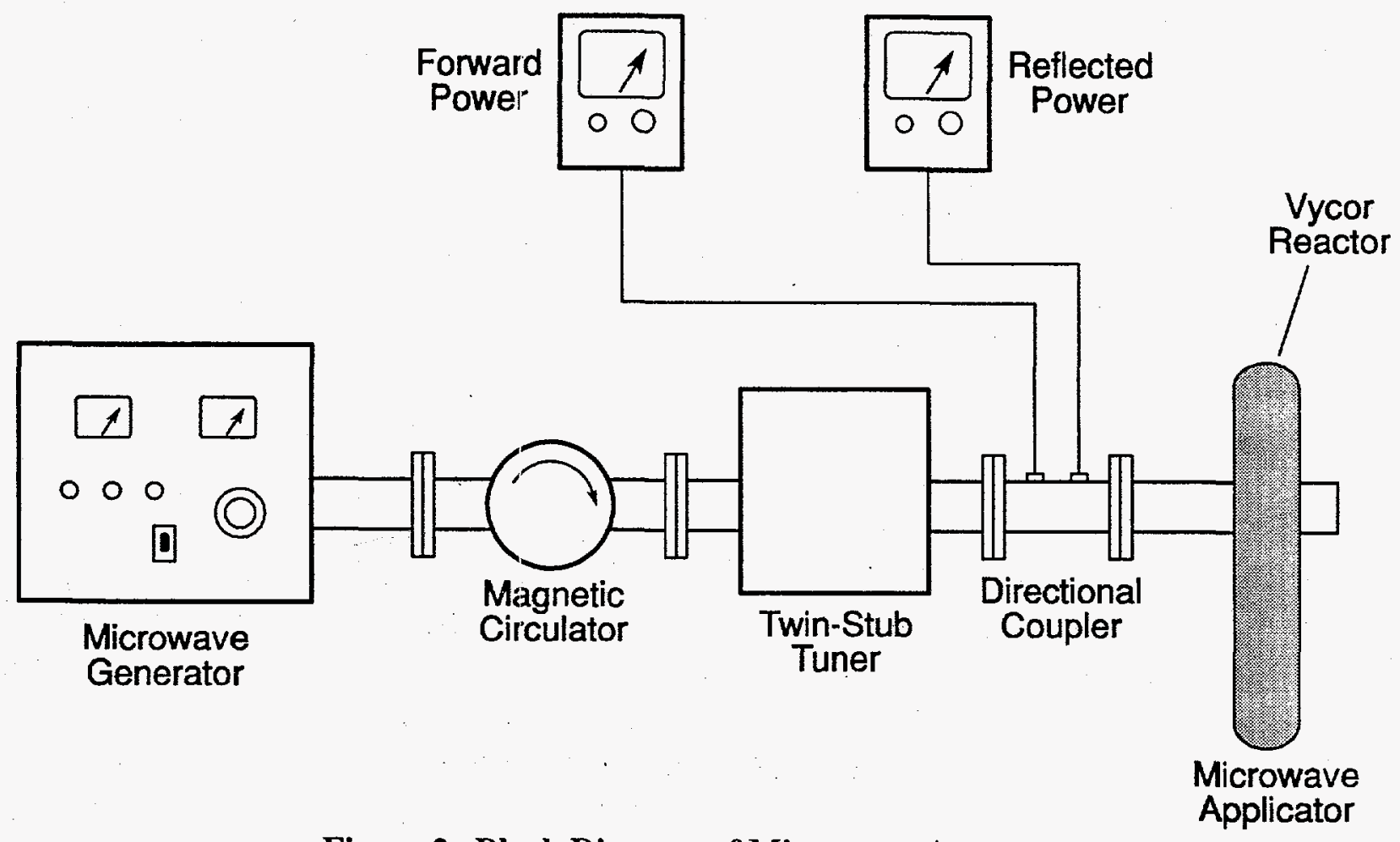

Figure 2. Block Diagram of Microwave Apparatus

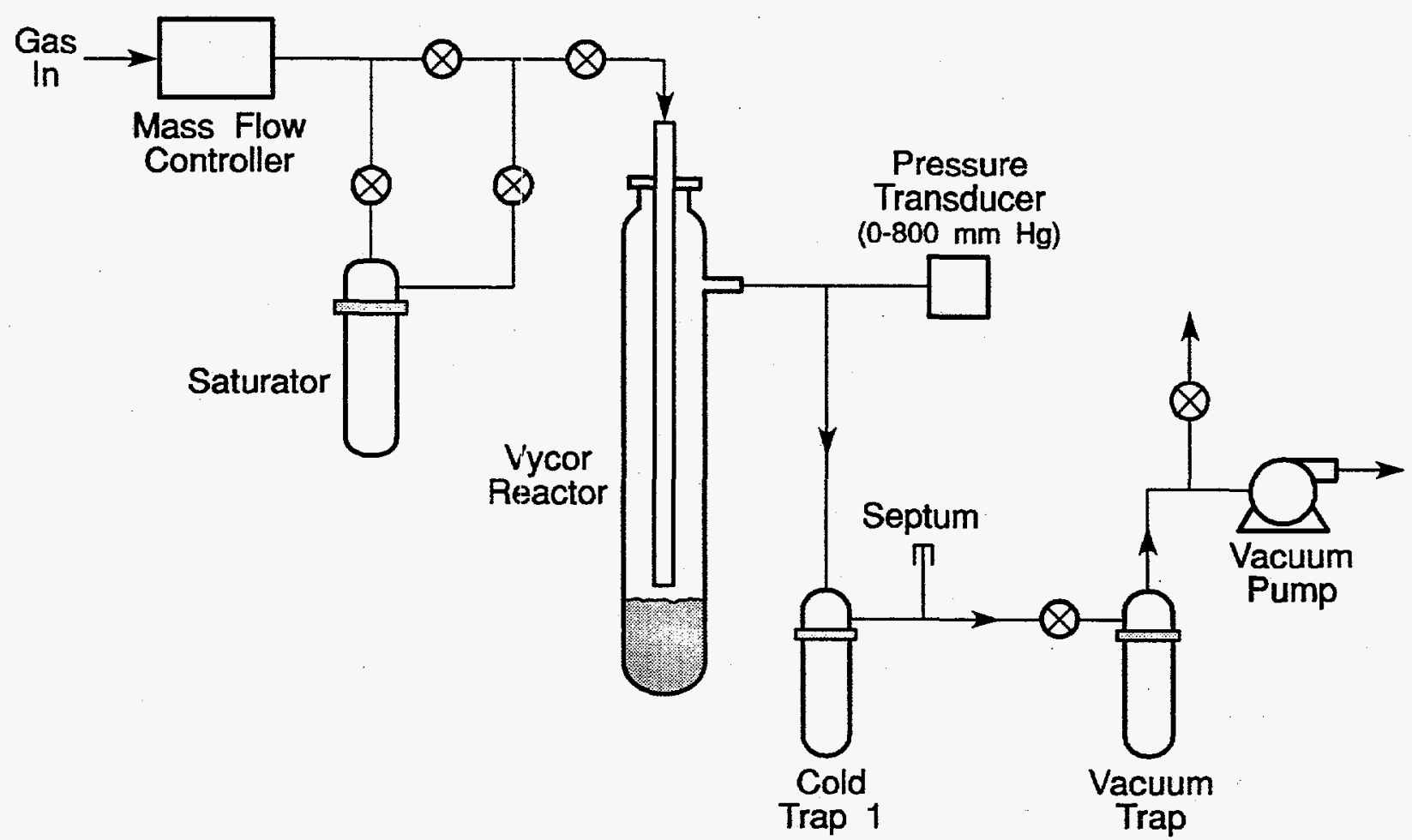

Figure 3. Schematic Diagram of Gas Flow System 
$\underline{\text { Series } 1}$

\section{RESULTS AND DISCUSSION}

In the Series 1 experiments high-sulfur asphalt samples were exposed to $\mathrm{H}_{2}, \mathrm{He}, \mathrm{CH}_{4}$, or $\mathrm{CH}_{4} / \mathrm{H}_{2} \mathrm{O}$ plasmas. For these experiments, the asphalt sample was heated to $120^{\circ} \mathrm{C}$ and gas flow was established at $36 \mathrm{scc} / \mathrm{min}(\sim 100 \mathrm{mMol} / \mathrm{hr})$. Microwave power was set at $\sim 200$ watts and remained constant throughout the test series. The interior reactor tube was adjusted so that its outlet end was fixed $\sim 8 \mathrm{~mm}$ above the surface of the asphalt. Samples were exposed to the plasma for 165 minutes at a pressure of 6 torr $(0.8 \mathrm{kPa})$, except for one test with hydrogen plasma in which the pressure was 15 torr $(2.0 \mathrm{kPa})$. After each test, the cold trap and reactor were rinsed with methylene chloride and the rinsings were combined to form a composite sample.

Table 1 lists product distribution and conversion to distillable liquids and gas for these tests. Conversions are listed as percent of feed: (weight of distillate or weight of gas)/(weight of feed) $\mathrm{x} 100$ and as percent of product: (weight of distillate or weight of gas)/(weight of distillate + weight of gas) $\times 100$. Table 2 shows the results of $\mathrm{C}, \mathrm{H}, \mathrm{N}, \mathrm{S}$ elemental analysis of the original asphalt and the combined reaction products. Test 1-1 served as a control with no plasma. Temperature, pressure, and flow were the same as used in the other tests.

Table 1. Conversion and Product Distribution for Series 1 Experiments

\begin{tabular}{ccccccc}
\hline & & \multicolumn{2}{c}{ distillate } & \multicolumn{2}{c}{ gas } & total \\
Test \# & gas & \% feed & \% prod & \% feed & \% prod & \% feed \\
\hline $1-1$ & $\mathrm{H} 2$ & 0.0 & 0.0 & 0.2 & 100.0 & 0.2 \\
$1-2$ & $\mathrm{He}$ & 0.2 & 5.3 & 4.1 & 94.7 & 4.3 \\
$1-3$ & $\mathrm{H} 2$ & 2.4 & 14.3 & 14.5 & 85.7 & 17.0 \\
$1-4$ & $\mathrm{CH} 4$ & 5.1 & 43.4 & 6.7 & 56.6 & 11.8 \\
$1-5$ & $\mathrm{CH} 4 / \mathrm{H} 2 \mathrm{O}$ & 4.4 & 37.8 & 7.2 & 62.2 & 11.6 \\
$1-6$ & $\mathrm{H} 2$ & 0.2 & 10.7 & 10.4 & 97.8 & 10.7 \\
\hline
\end{tabular}

Table 2. C, H, N, S Analyses of Combined Liquid Products From Series 1 Experiments

\begin{tabular}{cccccc}
\hline Test \# & $\mathrm{C}$ & $\mathrm{H}$ & $\mathrm{N}$ & $\mathrm{S}$ & $\mathrm{H} / \mathrm{C}$ \\
\hline feed & 81.4 & 10.2 & 0.08 & 7.3 & 1.50 \\
$1-1$ & 80.7 & 10.5 & 0.06 & 7.7 & 1.57 \\
$1-2$ & 81.2 & 10.9 & 0.04 & 6.9 & 1.60 \\
$1-3$ & 81.7 & 10.2 & 0.07 & 7.1 & 1.49 \\
$1-4$ & 82.0 & 10.3 & 0.05 & 6.7 & 1.15 \\
$1-5$ & 82.0 & 10.2 & 0.10 & 6.8 & 1.49 \\
$1-6$ & 80.7 & 11.2 & 0.07 & 7.0 & 1.68 \\
\hline
\end{tabular}


Elemental analyses of the original asphalt and the combined liquid reaction products for the Series 1 tests show no significant reduction in sulfur after exposure to the plasmas. From these data it does not appear that reactive species in the plasma selectively abstract sulfur from the hydrocarbon matrix. In view of the fact that the elemental composition of the product liquid was very similar to that of the feedstock, it appears that carbon, hydrogen, and sulfur were abstracted nearly stoichiometrically in the product gas. Conversion to distillable liquids was minimal in all the tests, and these liquids were not analyzed separately. Therefore, whether these liquids were low in sulfur was not determined.

In a study on the cracking of Athabasca bitumen residuum, Sanford (1994) noted that very little sulfur was removed from the hydrocarbon when conversions were low. Based on Sanford's work and the Series 1 test results, it was decided that higher conversions would be needed to evaluate the potential of plasma desulfurization.

\section{Series 2}

In the Series 2 experiments, four tests were conducted to explore the effect of sample temperature and location of the sample with respect to the discharge on conversion to distillable liquids. All four tests used hydrogen plasma with the inlet hydrogen flow maintained at 36 $\mathrm{scc} / \mathrm{min}$ and a reactor pressure of 6 torr $(0.8 \mathrm{kPa})$.

For Test 1 , the asphalt sample was heated to $160^{\circ} \mathrm{C}$ and exposed to hydrogen plasma for 270 minutes. At the start of this test, the outlet end of the interior tube was $\sim 8 \mathrm{~mm}$ above the surface of the asphalt. This distance decreased due to slippage of the interior tube in the O-ring sealed fitting as the test progressed. At the end of the test, the interior tube had slipped to where its end was about even with the surface of the asphalt.

In Test 2, the sample was heated to $188^{\circ} \mathrm{C}$ and exposed to hydrogen plasma for 166 minutes. The outlet end of the interior tube was fixed at $\sim 8 \mathrm{~mm}$ above the surface of the asphalt.

For Test 3, the asphalt was moved closer to the microwave applicator so that the surface of the asphalt was just below the bottom of the waveguide. The asphalt was preheated to $180^{\circ} \mathrm{C}$ and exposed to the hydrogen plasma for 25 minutes.

In Test 4 , the asphalt was preheated to $180^{\circ} \mathrm{C}$ and exposed to the plasma for 790 minutes. The cold trap was weighed at intervals as the test progressed. The end of the interior plasma tube was fixed at $8 \mathrm{~mm}$ above the asphalt surface for 700 minutes then lowered incrementally over the next 90 minutes so that its outlet end was about even with the surface of the asphalt at the end of the test. 
Table 3 lists conversions and product distribution for the Series 2 experiments. Conversion was calculated as: [(weight of feed) - (weight of $\mathrm{MeCl}_{2}$ soluble resid)]/(weight of feed) $x$ 100. For the purpose of these tests, the methylene chloride soluble material remaining in the reactor after exposure to the plasma was considered to be unconverted. It is interesting to note that methylene chloride insoluble solids were formed in similar amounts in all the tests, and there was no apparent correlation between solids formation and degree of conversion. The first test seemed to form the most distillate, but this result is suspect because there was a leak in the reactor during the first half of the test.

Table 3. Conversion and Product Distribution for Series 2 Experiments

\begin{tabular}{cccccccc}
\hline & total & \multicolumn{2}{c}{ distillate } & \multicolumn{2}{c}{ solids } & \multicolumn{2}{c}{ gas } \\
Test \# & \% feed & \% feed & \% prod. & \% feed & \% prod. & \% feed & \% prod. \\
\hline $2-1$ & 31.3 & 8.2 & 26.2 & 3.6 & 11.3 & 19.5 & 62.4 \\
$2-2$ & 32.8 & 6.1 & 18.5 & 4.5 & 13.7 & 22.2 & 67.8 \\
$2-3$ & 29.7 & 5.9 & 20.0 & 4.6 & 15.6 & 19.2 & 64.4 \\
$2-4$ & 45.4 & 7.0 & 15.3 & 3.6 & 7.9 & 34.8 & 76.7 \\
\hline
\end{tabular}

Figure 4 shows distillate production for the length of time the asphalt sample was exposed to hydrogen plasma. The distance between the discharge and the asphalt surface was set at $8 \mathrm{~mm}$ for the first 700 minutes of the experiment, then gradually reduced for the remaining 90 minutes. Note that distillate production increased significantly as the distance between the discharge and the asphalt surface was decreased.

In this test, 0.11 grams of distillate was produced during the first 700 minutes of exposure to the hydrogen plasma with the outlet of the interior tube $8 \mathrm{~mm}$ above the asphalt. Nearly twice this amount ( 0.20 grams) was produced in the final 90 minutes with the end of the interior tube lowered to just above the surface of the asphalt.

Figure 5 shows the results of simulated distillation of the liquid collected in the cold trap for the Series 2 tests. For each test, about $50 \%$ of the distillate was light gas oil $\left(195-340^{\circ} \mathrm{C}\right)$. Test 3 , in which the asphalt was placed near the discharge, produced more heavy distillate ( $>340$ ${ }^{\circ} \mathrm{C}$ ), while lower boiling liquids were favored in test 2 with the sample further from the discharge.

The results of the Series 2 experiments indicated that sample temperature had a negligible effect on distillate production. However, the distance between the discharge and the sample surface strongly influenced distillate production. 


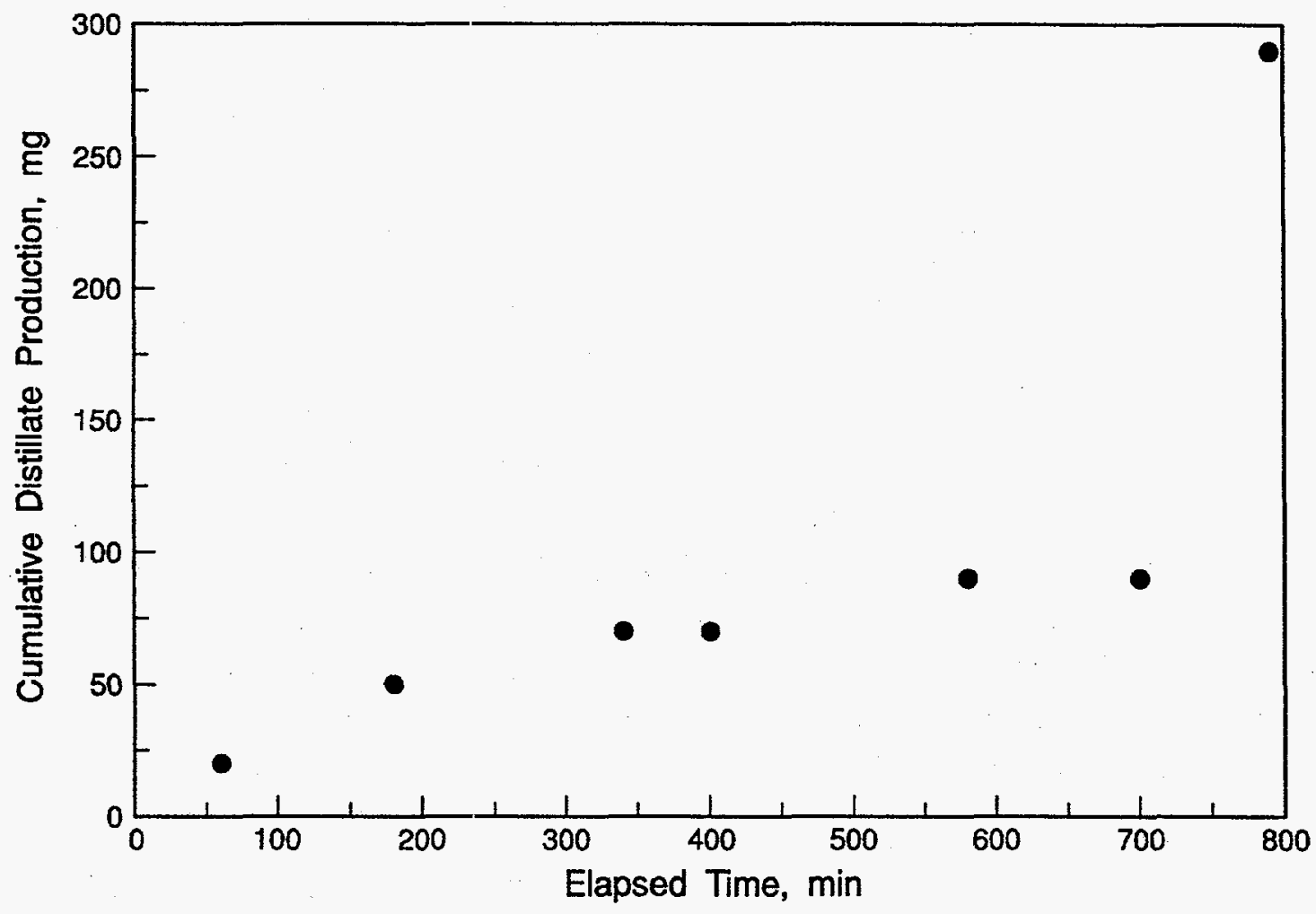

Figure 4. Distillate Production vs. Time, Experiment 2-4

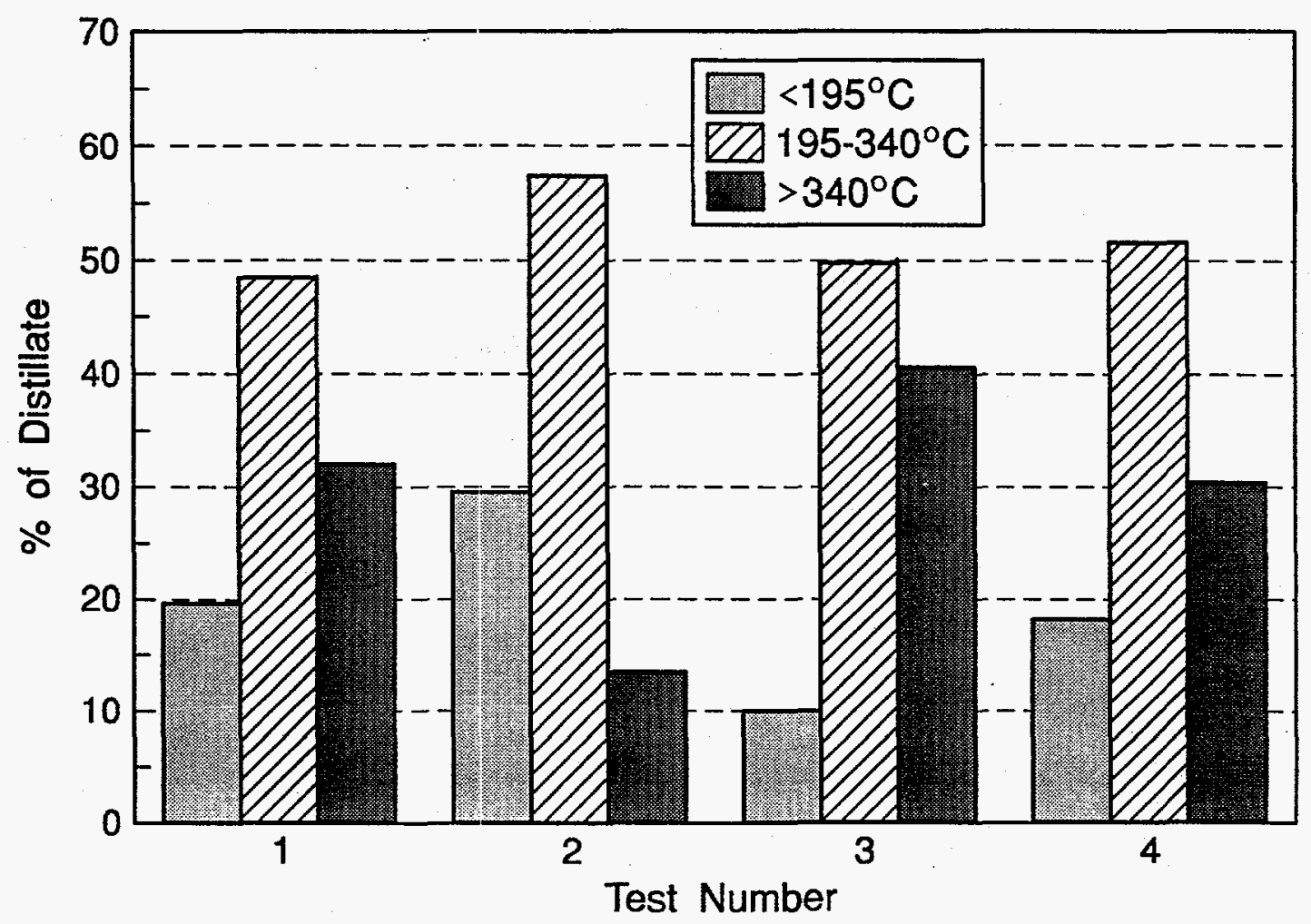

Figure 5. Results of Simulated Distillation of Distillate Product From Series 2 Tests 


\section{$\underline{\text { Series } 3}$}

In the Series 3 experiments, the distance between the plasma discharge and the sample was varied. For these experiments, gas flow was established at $36 \mathrm{scc} / \mathrm{min}(\sim 100 \mathrm{mMol} / \mathrm{hr})$ and microwave power was set as shown in Table 4. The asphalt sample was not heated for the Series 3 experiments. After each test, the reactor was rinsed with methylene chloride and the rinsings were filtered to provide separate samples of the methylene chloride soluble residual material and the insoluble solids.

Table 4 lists the experimental conditions, conversions, and product distribution for the Series 3 experiments. The distance column lists the initial distance in millimeters between the end of the interior plasma tube and the asphalt sample. Where this number is followed by a downward arrow, the interior plasma tube was moved incrementally toward the sample during the experiment so that its outlet was $\sim 1 \mathrm{~mm}$ from the bottom of outer tube at the end of the test. Where the distance is followed by an upward arrow, the sample was moved closer to the microwave applicator as the test progressed.

Table 4. Experimental Conditions, Conversion, and Product Distribution for Series 3 Experiments

\begin{tabular}{ccccccccccccc}
\hline test \# & gas & $\begin{array}{c}\text { press. } \\
\text { (torr) }\end{array}$ & $\begin{array}{c}\text { power } \\
(\mathrm{W})\end{array}$ & $\begin{array}{c}\text { distance } \\
(\mathrm{mm})\end{array}$ & $\begin{array}{c}\text { conv } \\
\text { feed }\end{array}$ & $\begin{array}{c}\text { distillate } \\
\text { feed }\end{array}$ & $\begin{array}{c}\% \\
\text { prod }\end{array}$ & $\begin{array}{c}\text { gas } \\
\text { feed }\end{array}$ & $\begin{array}{c}\text { \%olids } \\
\text { prod }\end{array}$ & $\begin{array}{c}\% \\
\text { feed }\end{array}$ & $\begin{array}{c}\% \\
\text { prod }\end{array}$ \\
\hline $3-1$ & $\mathrm{H}_{2}$ & 6 & 260 & 8 & 54.0 & 10.5 & 19.4 & 33.5 & 62.0 & 10.0 & 18.5 \\
$3-2$ & $\mathrm{CH}_{4}$ & 6 & $260 / 300$ & 8 & 60.0 & 10.5 & 17.5 & 32.5 & 54.2 & 17.0 & 28.3 \\
$3-3$ & $\mathrm{~N}_{2}$ & 6 & 260 & 8 & 37.6 & 5.0 & 13.2 & 23.8 & 63.2 & 8.9 & 23.7 \\
$3-4$ & $\mathrm{H}_{2}$ & 6 & 260 & $8 \downarrow$ & 93.5 & 26.0 & 27.8 & 50.5 & 54.0 & 17.0 & 18.2 \\
$3-5$ & $\mathrm{CH}_{4}$ & 6 & 260 & $8 \downarrow$ & 88.7 & 18.6 & 21.0 & 52.9 & 59.7 & 17.2 & 19.3 \\
$3-6$ & $\mathrm{~N}_{2}$ & 6 & 260 & $8 \downarrow$ & 83.0 & 17.0 & 20.5 & 46.0 & 55.4 & 20.0 & 24.1 \\
$3-7$ & $\mathrm{H}_{2}$ & 12 & 260 & $2 \downarrow$ & 67.0 & 29.1 & 43.4 & 28.6 & 42.6 & 9.4 & 14.0 \\
$3-8$ & $\mathrm{~N}_{2}$ & 6 & 260 & $2 \downarrow$ & 83.7 & 19.7 & 23.5 & 46.8 & 55.9 & 17.2 & 20.6 \\
$3-9$ & $\mathrm{H}_{2}$ & 6 & 200 & $2 \downarrow$ & 60.7 & 26.9 & 44.3 & 27.9 & 45.9 & 6.0 & 9.8 \\
$3-10$ & $\mathrm{~N}_{2}$ & 6 & 200 & $2 \downarrow$ & 58.3 & 18.6 & 31.9 & 31.4 & 53.8 & 8.3 & 14.3 \\
$3-11$ & $\mathrm{CH}_{4}$ & 6 & 260 & $25 \uparrow$ & 54.5 & 19.0 & 34.9 & 21.5 & 39.4 & 14.0 & 25.7 \\
$3-12$ & $\mathrm{H}_{2}$ & 6 & 260 & $40 \uparrow$ & 89.1 & 14.4 & 15.9 & 59.7 & 67.0 & 14.9 & 16.8 \\
$3-13$ & $\mathrm{H}_{2}$ & 6 & 250 & $40 \uparrow$ & 39.5 & 5.5 & 13.9 & 25.0 & 63.3 & 9.0 & 22.8 \\
$3-14$ & $\mathrm{H}_{2}$ & 6 & 700 & 0 & 100 & 0.0 & 0.0 & 68.7 & 68.7 & 31.3 & 31.3 \\
$3-15$ & $\mathrm{~N}_{2}$ & 6 & 0 & & 48.8 & 29.4 & 60.2 & 5.5 & 11.2 & 13.9 & 28.6 \\
$3-16$ & $\mathrm{~N}_{2}$ & 40 & 0 & & 84.7 & 39.3 & 46.4 & 30.6 & 36.1 & 14.8 & 17.5 \\
\hline
\end{tabular}


In Tests 3-1, 3-2, and 3-3, the interior reactor tube was adjusted so that its outlet end was fixed $\sim 8 \mathrm{~mm}$ above the surface of the asphalt. In these experiments, the samples were exposed to hydrogen, methane, or nitrogen plasmas for 60 minutes. In Test 3-2, the microwave power was increased to $\sim 300$ watts after about 20 minutes in order to provide a more stable plasma. The tests using hydrogen and methane plasmas showed higher conversion and produced more than twice as much distillate as the test using the nitrogen plasma. In all the tests, the majority of the product was gas, and all the tests produced significant amounts of methylene chloride insoluble solids.

Tests 3-4, 3-5, and 3-6 were essentially identical to Tests 3-1, 3-2, and 3-3 except that the outlet of the interior reactor tube was moved incrementally toward the asphalt sample as these tests progressed. Samples were exposed to hydrogen, methane, or nitrogen plasmas for 60 minutes with microwave power set at 260 watts. All of these tests showed a higher conversion, more distillate production, and more of the product as distillate than the corresponding tests in which the distance from the end of the interior plasma tube to the sample was fixed. As in the previous tests, the experiments that used hydrogen and methane plasmas showed higher conversion and produced more distillate than the test that used the nitrogen plasma.

Tests 3-7 and 3-8 duplicated Tests 3-4 and 3-6 except for the initial position of the outlet end of the interior reactor tube. In Tests 3-7 and 3-8, the outlet end of the interior reactor tube was moved incrementally toward the sample from an initial position $2 \mathrm{~mm}$ above the asphalt surface. The samples were exposed to hydrogen or nitrogen plasmas for 60 minutes with microwave power set at 260 watts. The experiment that used the hydrogen plasma showed a lower overall conversion but produced significantly more distillate than the test that used the nitrogen plasma. Compared to the corresponding tests that used an 8-mm initial distance between the interior plasma tube and the sample, both of these tests showed increased distillate production. Compared to the corresponding tests that used an 8-mm initial distance, overall conversion was lower for the test using hydrogen and slightly higher for the test using nitrogen.

Tests 3-9 and 3-10 duplicated Tests 3-7 and 3-8 except for the microwave power. In these tests, the samples were exposed to hydrogen or nitrogen plasmas for 60 minutes with microwave power set at 200 watts. The experiment that used the hydrogen plasma showed a slightly higher overall conversion and produced significantly more distillate than the test that used the nitrogen plasma. Compared to the corresponding tests that used higher power, these experiments resulted in lower overall conversion and less distillate production. Distillate represented a larger percentage of the total product for both tests than for the corresponding tests that used higher power. 
In Tests 3-11, 3-12, and 3-13, the sample was moved closer to the microwave applicator as the tests progressed. In these tests, the position of the interior tube with respect to the sample surface remained constant while the entire reactor was raised so that the distance between the sample and the microwave applicator was decreased.

In Test 3-11, the sample was exposed to a methane plasma for 30 minutes. As the test progressed, the reactor was raised so that the distance between the sample and the microwave applicator was decreased to half the initial distance by the end of the test. This test resulted in a lower overall conversion than either of the previous tests that used methane plasmas. However, more feed was converted to distillate, and distillate represented a larger percentage of the total product in this test than in previous tests using methane plasmas.

In Test 3-12, the sample was exposed to a hydrogen plasma for 169 minutes. As the test progressed, the reactor was raised so that the sample was inside the microwave applicator at the end of the test. This test produced considerably less distillate than the tests using the hydrogen plasma in which the interior plasma tube was lowered toward the sample even though overall conversion was high. The major product from this test was gas. Solids and distillate were produced in nearly equal amounts.

In Test 3-13, the sample was exposed to a hydrogen plasma for 66 minutes. As the test progressed, the reactor was raised so that the sample was just below the microwave applicator at the end of the test. These conditions gave a low overall conversion with minimal distillate production. The conversion and product distribution for this test were very similar to those of Test 3-3.

In Test 3-14, the asphalt was placed within the plasma rather than downstream of the discharge. This experiment used a Kenmore kitchen-type microwave oven and a $250-\mathrm{ml}$ roundbottom quartz flask configured to maintain a flow of hydrogen at a pressure of $\sim 6$ torr. The asphalt was coated around the circumference of the flask, and the flask was placed in the microwave oven fitted with a choke through which the gas flow connections were made. In this experiment, the sample was exposed directly to the hydrogen plasma for 15 minutes. This experiment resulted $100 \%$ conversion to gas and solids, with no distillate production.

In Tests 3-15 and 3-16, the sample was heated under nitrogen in the absence of a plasma using the same reactor and gas flow rate as in the tests with a plasma. In Test 3-15, the sample was heated for 30 minutes using a small flame from a laboratory burner. In Test 3-16, the sample was heated at $475^{\circ} \mathrm{C}$ for 60 minutes in an electric tube furnace. In Test 3-15, about $50 \%$ of the sample was converted to products. The majority of the product was distillate, with very little gas production. Test 3-16 gave a greater overall conversion with increased distillate and gas production. Solids were produced in similar amounts in both of these thermal tests. 
The production of distillate in the tests that used nitrogen plasmas shows that some distillate was produced by strictly thermal processes. A probable thermal influence is also indicated by the changes in distillate production associated with changes in position of the sample with respect to the discharge. However, more distillate was always produced in the tests that used plasmas containing potentially reactive hydrogen species than in similar tests that used nonreactive nitrogen plasmas. This result indicates that reactive hydrogen in the plasma may be responsible for some conversion of heavy oil to distillate.

For similar conversions, the strictly thermal tests (3-15 and 3-16) showed more distillate and less gas production than the tests that used plasmas. This result may be explained by conversion in the vapor phase of some of the distillate to gas as the products passed, albeit briefly, through the plasma zone.

Tables 5, 6, and 7 show the results of $\mathrm{C}, \mathrm{H}, \mathrm{N}, \mathrm{S}$ elemental analyses of the feedstock, distillate product, methylene chloride soluble resid, and methylene chloride insoluble solids from selected Series 3 tests. Tests marked with an asterisk $\left(^{*}\right)$ in the sulfur column did not generate sufficient amounts of distillate or solids for sulfur analyses. Duplicate analyses of several samples did not exhibit good repeatability. Therefore, these results are presented only as a qualitative indicator of whether the plasma reactions were effective in removing sulfur from the hydrocarbon matrix.

The results of the elemental analyses of the various products of these exploratory experiments indicate that exposure to hydrogen-rich plasmas does not selectively abstract sulfur from the hydrocarbon matrix. While some tests show a modest reduction in sulfur in the distillate product, the greatest reduction shown $(28 \%)$ is too small to be significant in terms of a desulfurization process. Also note that the same reduction in sulfur was attained by simply heating the sample under nitrogen with no plasma exposure (Test 3-15).

Table 5. C, H, N, S Analyses of Distillate Product From Selected Series 3 Experiments

\begin{tabular}{cccccc}
\hline Test \# & $\mathrm{C}$ & $\mathrm{H}$ & $\mathrm{N}$ & $\mathrm{S}$ & $\mathrm{H} / \mathrm{C}$ \\
\hline feed & 80.7 & 10.4 & 0.7 & 6.1 & 1.55 \\
$3-12$ & 82.2 & 8.2 & 0.7 & $*$ & 1.20 \\
$3-13$ & 75.8 & 8.4 & 0.8 & 4.4 & 1.33 \\
$3-2$ & 87.8 & 7.5 & 0.8 & $*$ & 1.03 \\
$3-5$ & 84.5 & 8.2 & 0.9 & 7.5 & 1.16 \\
$3-6$ & 80.7 & 9.5 & 1.0 & 6.2 & 1.41 \\
$3-8$ & 81.9 & 9.8 & 0.8 & 4.4 & 1.67 \\
$3-15$ & 81.9 & 11.4 & 0.5 & 4.4 & 1.67 \\
$3-16$ & 79.8 & 11.2 & 0.5 & $*$ & 1.68 \\
\hline
\end{tabular}


Table 6. C, H, N, S Analyses of Methylene Chloride Soluble Resid From Selected Series 3 Experiments

\begin{tabular}{cccccc}
\hline Test \# & $\mathrm{C}$ & $\mathrm{H}$ & $\mathrm{N}$ & $\mathrm{S}$ & $\mathrm{H} / \mathrm{C}$ \\
\hline feed & 80.7 & 10.4 & 0.7 & 6.1 & 1.55 \\
$3-12$ & 77.7 & 6.8 & 1.1 & 4.2 & 1.05 \\
$3-13$ & 58.0 & 8.7 & 1.0 & 6.0 & 1.49 \\
$3-2$ & 92.1 & 8.8 & 1.6 & 5.6 & 1.15 \\
$3-5$ & 58.9 & 7.3 & 1.1 & 5.9 & 1.49 \\
$3-6$ & 78.1 & 8.1 & 1.6 & 6.6 & 1.24 \\
$3-8$ & 71.5 & 7.6 & 1.6 & 6.4 & 1.28 \\
$3-15$ & 76.2 & 9.5 & 1.1 & 5.3 & 1.50 \\
$3-16$ & 78.5 & 8.9 & 1.3 & 4.7 & 1.36 \\
\hline
\end{tabular}

Table 7. C, H, N, S Analyses of Methylene Chloride Insoluble Solids From Selecte Series 3 Experiments

\begin{tabular}{cccccc}
\hline Test \# & $\mathrm{C}$ & $\mathrm{H}$ & $\mathrm{N}$ & $\mathrm{S}$ & $\mathrm{H} / \mathrm{C}$ \\
\hline $3-12$ & 69.0 & 4.0 & 2.2 & 4.8 & 0.70 \\
$3-13$ & 86.2 & 2.9 & 1.9 & 3.4 & 0.40 \\
$3-2$ & 87.1 & 3.5 & 1.7 & 2.0 & 0.48 \\
$3-5$ & 74.9 & 4.4 & 2.3 & 4.5 & 0.70 \\
$3-6$ & 74.7 & 3.5 & 2.6 & $*$ & 0.56 \\
$3-8$ & 79.0 & 4.8 & 2.5 & 4.5 & 0.73 \\
$3-15$ & 84.8 & 3.5 & 2.5 & $*$ & 0.50 \\
$3-16$ & 84.1 & 5.0 & 2.5 & 4.6 & 0.71 \\
\hline
\end{tabular}

In general, the distillate product from the tests that used reactive plasmas (generated from either hydrogen or methane) appears to be more aromatic than the feedstock and the corresponding products from the tests that used nonreactive nitrogen plasma or simple heating without plasma. This result indicates that the reactive plasmas under the conditions used for these tests do not add hydrogen but rather tend to abstract hydrogen from the hydrocarbon matrix, forming aromatics that are more stable in the plasma environment (Boenig 1988). While this result appears to be at odds with those reported by Amano and co-workers, Amano used a much greater distance between the sample and discharge than was used in this study. The greater distance used by Amano would tend to limit thermal effects of the plasma and thus could lead to more saturated products. 


\section{SUMMARY AND CONCLUSIONS}

Exploratory experiments have been conducted on the use of various plasmas as an alternative to catalytic desulfurization processes. In these exploratory experiments, samples of high-sulfur asphalt were exposed to microwave-induced plasmas, and conversion to distillate, gas, and solids was measured. The results of these experiments indicate that there was generally some reaction of the plasma species with the asphalt feedstock, but the results did not indicate that reactive plasma species selectively abstracted sulfur from the hydrocarbon matrix to any great extent.

One test using hydrogen plasma produced a distillate with $28 \%$ less sulfur than the feedstock; however, this level of desulfurization is minimal when compared to that obtained by catalytic hydrodesulfurization processes. This same level of sulfur removal was attained in a control experiment in which the asphalt was simply heated under nitrogen without the use of plasma. The results of these exploratory experiments do not indicate that heavy oils can be desulfurized using a simple plasma process. 


\section{REFERENCES}

Amano, A., M. Yamada, T. Shindo, and T. Akakura, 1984, "Coal Liquefaction Induced by Hydrogen Atoms." Fuel, 63: 718-719.

Amano A., M. Yamada, T. Shindo, and T. Akakura, 1985, "Characterization of Liquid Product from the Reaction of Coal with Hydrogen Atoms." Fuel, 64: 123-124

Boenig, Herman V., Fundamentals of Plasma Chemistry and Technology, Technomic Publishing Company, Inc., Lancaster PA, 1.988, 70 pp.

Cominsky, R.J., J.S. Moulthorp, W.E. Elmoreand, T.W. Kennedy, "SHRP Materials Reference Library Asphalt Selection Process: Rept. No. SHRP-IR-A-89-002," Strategic Highway Research Program, Washington, DC, 1989, 31 pp.

Gary and Handwerk, 1975, Petroleum Refining Technology and Economics, Marcel Dekker, Inc., $32 \mathrm{pp}$.

Haugsjaa, Paul O., 1986, "Microwave discharges in termination fixtures: An improved laboratory technique for exciting electrodeless discharges." Rev. Sci. Instrum. 57 (2): 167-169pp.

Sanford, Emerson C., "Influence of Hydrogen and Catalyst on Distillate Yields and the Removal of Heteroatoms, Aromatics, and CCR over a Wide Range of Conversions," Energy and Fuels, 1994, 8, 1276-1288.

Speight, James G., 1981, The Desulfurization of Heavy Oils and Residua, Marcel Dekker, Inc., pp 88-118 